\title{
SUBSTANCE USE AMONG HEALTHCARE WORKERS IN A NIGERIAN TERTIARY HOSPITAL
}

\section{${ }^{1}$ Omole VN,${ }^{2}$ Irohibe $\mathrm{CK}_{,},{ }^{1}$ Usman $\mathrm{NO}_{,}{ }^{3}$ Audu $\mathrm{O},{ }_{,}^{4} \mathrm{Jamda} \mathrm{MA}^{5}$ Baduku AS' Maigari JM ${ }^{6}$}

\author{
${ }^{1}$ Department of Community Medicine, College of Medicine, Kaduna State University, \\ Kaduna, Nigeria \\ ${ }^{2}$ Department of Obstetrics and Gynaecology, Ahmadu Bello University Teaching Hospital, \\ Zaria, Nigeria \\ ${ }^{3}$ Department of Epidemiology \& Community Health, College of Health Sciences, \\ Benue State University, Makurdi, Nigeria \\ ${ }^{4}$ Department of Community Medicine, College of Health Sciences, University of Abuja, Nigeria \\ ${ }^{5}$ Department of Sociology, Faculty of Social \& Management Sciences, Kaduna State University, \\ Kaduna, Nigeria \\ ${ }^{6}$ Department of Psychiatry, College of Medicine, Kaduna State University, Kaduna, Nigeria
}

Correspondences and reprint request to: Dr. V.N. Omole, Department of Community Medicine, Faculty of Clinical Sciences, College of Medicine, Kaduna State University, Kaduna, Nigeria Email: nvable110@yahoo.com

\begin{abstract}
Background: Research studies abound on substance use among healthcare workers (HCWs) in the western world, but a paucity of such information is the case in developing countries. Objectives: To determine the prevalence of substance use among HCWs in a Nigerian tertiary hospital and the variety of substances commonly used. Method: A cross-sectional study was conducted among 380 HCWs selected across 4 professional cadres by stratified random sampling method. Results: About $85.5 \%$ of the respondents were past and/ or current users of substances or substance-containing food items. Out of the 325 respondents who had ever used substances before, 208 (64\%) were current users- these represented $54.7 \%$ of the whole. Coffee, alcohol and kolanuts were most frequently used. Diazepam was the least used. Gender was a statistically significant determinant of substance use $(p<0.05)$. Conclusion: Substance use among HCWs carries grave implications for practitioners and patients alike. Further research towards unearthing and addressing the factors fueling this menace in developing countries will contribute immensely in resolving this challenge.
\end{abstract}

Keywords: Drugs, Healthcare workers (HCWs), Prevalence, Substance, Users

\section{INTRODUCTION}

Substance use is the consumption or administration of any physical matter (solid, liquid or gaseous); ranging from alcohol, tobacco and caffeine to illicit drugs. Substances often influence or alter an individual's mood and/or cognitive functions. Substance use often begins as a recreational (social)

\begin{tabular}{|l|l|}
\hline \multicolumn{2}{|c|}{ Access this article online } \\
\hline Quick Access Code & \\
\hline
\end{tabular}

or experimental habit. It is usually the doorway to substance misuse and/or abuse, which often come with the risk of addictive dependence, as the substances involved are usually psycho-active in nature. Attempts have been made to distinguish between the different terminologies. However, in actual fact, there is only a thin line that separates substance use from misuse and abuse. In reality, they are actually a continuum. ${ }^{1}$ Misuse is the consumption or administration of a substance for a purpose inconsistent with medical or legal guidelines. ${ }^{2}$ The World Health Organisation (WHO) defines 
substance abuse as "the harmful or hazardous use of psycho-active substances, including alcohol and illicit drugs".

It is further defined by the Diagnostic and Statistical Manual of Mental Disorders (DSM-IV) as a "maladaptive pattern of use (of psycho-active substances) indicated by continued use despite knowledge of having a persistent or recurrent social, occupational, psychological or physical problem that is caused or exacerbated by the use [or by] recurrent use in situations in which it is physically hazardous". ${ }^{4}$ Irrespective of the definition or school of thought, it is generally a unanimous and universal consensus that the use of psycho-active substances is potentially harmful and hazardous to the users, as it interferes with their health, work and/or social relationships. ${ }^{3,5}$ It ultimately impacts severely and detrimentally on the overall physical, psychological, social and economic well-being of the users and affects others associated with or closely connected to them negatively. ${ }^{6,7}$ Established and documented sequelae of substance abuse include the development of dependence syndrome, which is a cluster of adverse behavioural, cognitive and physiological phenomena. ${ }^{1,3}$

Substances typically implicated vary from those which are viewed in certain socio-cultural contexts as socially "acceptable" or tolerated, to those which not only carry a social stigma, but are out rightly illicit. ${ }^{8,9}$ While the former include tobacco, alcohol, caffeine-containing items like coffee, kolanuts etc, on one hand; the latter include cannabis, cocaine, heroin, marijuana etc. ${ }^{5,6}$ Psychoactive prescription drugs such as benzodiazepines (diazepam, bromazepam etc), opioids (morphine, codeine, tramadol, fentanyl, pethidine, methadone etc), amphetamines and barbiturates are also subject to abuse. ${ }^{3}$ Substance use disorders are reported to be associated with a significant disease burden and the highest mortality among all mental and behavioural disorders. ${ }^{10}$ The 2017 World Drug Report estimates that globally, about a quarter of a billion people (about $5 \%$ of the world's adult population) used psychoactive substances at least once in the year 2015; and about 29.5 million of these drug users (representing 0.6\% of the global adult population) suffered from substance use disorders- experiencing drug dependence and requiring treatment. ${ }^{11}$ This resulted in an estimated 28 million years of "healthy" life (disability-adjusted life yearsDALYs) lost secondary to premature deaths and disabilities in 2015, globally. Substance use, misuse and abuse thus, constitute major public health concerns, particularly in urban areas, worldwide.

Furthermore, in recent times, substance abuse has become an increasingly topical issue in Nigeria, drawing attention from stakeholders within and outside the nation. ${ }^{12,13}$ The World Drug Report (2018) states that, "The extent of drug use in Nigeria is comparatively high when compared with the 2016 global annual prevalence of any drug use of $5.6 \%$ among the adult population". ${ }^{14}$ This trend has become a growing concern; particularly among younger age groups..$^{12-14}$ Thus, many studies have focused on this age group. However, substance use is not confined to this age bracket alone. Globally, other subsets of the general population have been reported to be prone to abusing diverse substances. These include athletes, celebrities, war veterans, prisoners, the homeless and destitute, ethnic (or racial) minorities and immigrants. ${ }^{15-17}$ This study aimed at determining the prevalence of and identifying the determinants of substance use among healthcare workers (HCWs) in a tertiary hospital in north-western Nigeria as well as the variety of substances commonly used.

This is a relevant sub-group to understudy in view of the precarious implications of substance use on both HCWs and the populace they serve. Consequences associated with this maybe personal, professional and/or social. They include a deterioration in the physical and mental health of HCWs, thus negatively impacting on the quality of health services they offer and also threatening the lives and well-being of the patients under their care. A dearth of information on this subject matter (among 
HCWs) exists in the developing world in its diverse aspects such as a lack of awareness of its existence and prevalence, the demographic profiles and background as well as the cadre and sub-specialties of HCWs frequently involved, predisposing factors, substances commonly implicated, early detection strategies and also intervention and rehabilitation programmes for HCWs affected. These constitute a knowledge gap that ought to be researched and addressed, in view of the negative consequences it carries on health service providers and end users of the services alike; particularly against the backdrop of the poor health indices as well as shortage of human resources for health and brain drain that characterise the health sector in the local context of many developing countries.

\section{MATERIALS AND METHOD}

Study Area: The study was conducted in Ahmadu Bello University Teaching Hospital (ABUTH), Shika-Zaria in Kaduna State, north-western Nigeria; which is the teaching hospital affiliated to the medical school of Ahmadu Bello University, Zaria. Established as Institute of Health in 1968, it transformed into Ahmadu Bello University Teaching Hospital in accordance with statute 15 of the University Law (Amendment Act Schedule 16) by the government of the former Northern Region of Nigeria. ${ }^{18}$ Its primary objective is the provision of facilities for the training of doctors, nursing and other medical personnel at both undergraduate and post-graduate levels.

Study Design: A descriptive, cross-sectional study design

Study Population: consisted of health workers falling within the categories of doctors, nurses, pharmacists and medical laboratory scientists.

Sample Size: The sample size was calculated using the formula:

$$
n=\underline{z^{2} p q} d^{2}
$$

Where,

$\mathrm{n}=$ the desired sample size

$\mathrm{z}=$ the standard normal deviate which corresponds to $95 \%$ confidence interval (normally setat 1.96) $\mathrm{p}=$ the prevalence of substance use as obtained from a similar study ${ }^{19}=42.8 \%$ (i.e., 0.428 )

$q=1-p=57.2 \%$ (i.e., 0.572 )

$\mathrm{d}=$ degree of precision $(0.05)$

$\mathrm{n}=(1.96)^{2} \times 0.428 \times 0.572$

$(0.05)^{2}$

$\mathrm{n}=376.19=376$

Operational Definition: substance use, in this context refers to the consumption or administration of any physical matter (solid, liquid or gaseous); ranging from those substances which are viewed in certain sociocultural contexts as socially "acceptable" or tolerated (such as alcohol, tobacco, over-thecounter drugs etc), to those which not only carry a social stigma, but are out rightly classified as illicit.

Sampling Method: Stratified random sampling method was used. In order to ensure an equitable representation, the health workers were first stratified according to their various professional cadres using the institutional nominal roll as the line list (namely- doctors, nurses, pharmacists and laboratory scientists). Subsequently, sampling was done in each stratum using simple random sampling technique. In the final sample size, each stratum consisted of its equivalent proportion of the various professional cadres in the hospital (i.e. in the estimated ratio of 3.8:5.1:0.3:0.76 for doctors: nurses: pharmacists: laboratory scientists, respectively)

Data Management: data collection was conducted using structured, close-ended, selfadministered questionnaires. Results were presented in form of tables and charts. Chi square $\left(x^{2}\right)$ test was used to test for associations; with $\mathrm{p}$-value set at 0.05

Ethical Considerations: informed consent was obtained from the respondents and confidentiality of information obtained was assured. 


\section{RESULTS}

Table 1: Socio-demographic Profile of Respondents $(\mathrm{n}=380)$

\begin{tabular}{|c|c|}
\hline Variable & \multirow{2}{*}{ Frequency (\%) } \\
\hline Age Group (Years) & \\
\hline $20-24$ & $8(2.1)$ \\
\hline $25-29$ & $107(28.2$ ) \\
\hline $30-34$ & $78(20.5)$ \\
\hline $35-39$ & $76(20.0)$ \\
\hline $40-44$ & $52(13.7)$ \\
\hline $45-49$ & $29(7.6)$ \\
\hline $50-54$ & $23(6.1)$ \\
\hline $55-59$ & $7(1.8)$ \\
\hline Total & $380(100.0)$ \\
\hline \multicolumn{2}{|l|}{ Sex } \\
\hline Male & $224(58.9)$ \\
\hline Female & $156(41.1)$ \\
\hline Total & $380(100.00)$ \\
\hline \multicolumn{2}{|l|}{ Cadre } \\
\hline $\begin{array}{l}\text { Doctors } \\
\text { Nurses }\end{array}$ & $\begin{array}{l}143(37.6) \\
195(51.3)\end{array}$ \\
\hline Pharmacists & $13(3.4)$ \\
\hline $\begin{array}{l}\text { Medical laboratory } \\
\text { scientists }\end{array}$ & $29(7.6)$ \\
\hline Total & 380 (100.00) \\
\hline
\end{tabular}

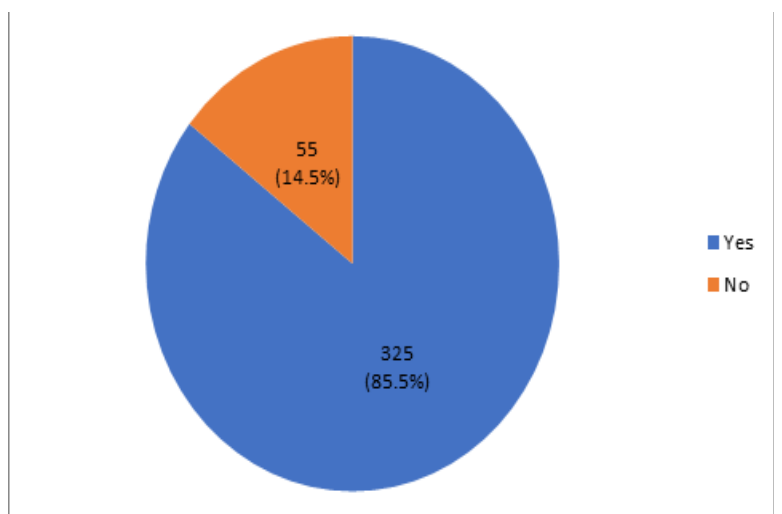

Figure 1: Previous and Current Use of Substances among Respondents $(n=380)$ 
Table 2: Current Use of Substances among Respondents $(n=325)$

\begin{tabular}{ll}
\hline Currently Using Substances & Frequency ( \%) \\
\hline Yes & $208(64.0)$ \\
No & $117(36.0)$ \\
\hline Total & $\mathbf{3 2 5 ( 1 0 0 . 0 )}$ \\
\hline
\end{tabular}

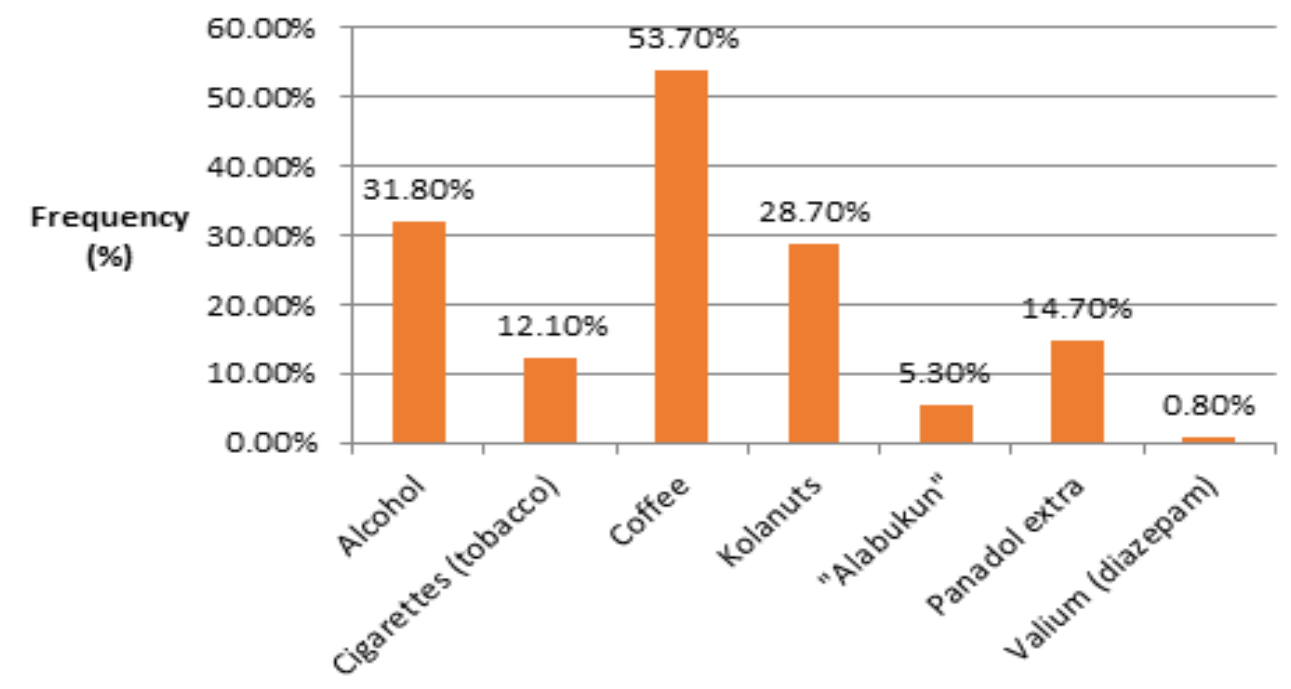

Figure 2: Distribution of Substances and Substance-containing Foods Used by Respondents (Multiple responses were entertained)

Table 3: Determinants of Current Substance Use among Respondents ( $n=325)$

\begin{tabular}{|c|c|c|c|c|c|}
\hline \multirow{2}{*}{ Variables } & \multirow{2}{*}{ Categories } & \multicolumn{2}{|c|}{ Current Substance Use } & \multirow{2}{*}{ Total } & \multirow{2}{*}{$\begin{array}{c}p \text {-value } \\
\left(x^{2}\right)\end{array}$} \\
\hline & & Yes & No & & \\
\hline \multirow[t]{5}{*}{ Age (years) } & $20-29$ & 63 & 43 & 106 & $p=0.64$ \\
\hline & $30-39$ & 82 & 44 & 126 & $(\mathrm{df}=3)$ \\
\hline & $40-49$ & 46 & 21 & 67 & \\
\hline & $50-59$ & 17 & 9 & 26 & \\
\hline & Total & 208 & 117 & 325 & \\
\hline \multirow[t]{3}{*}{ Sex } & Male & 106 & 74 & 180 & $p=0.03$ \\
\hline & Female & 102 & 43 & 145 & $(\mathrm{df}=1)$ \\
\hline & Total & 208 & 117 & 325 & \\
\hline \multirow[t]{6}{*}{ Cadre } & Doctors & 73 & 53 & 126 & \\
\hline & Nurses & 105 & 51 & 156 & $p=0.19$ \\
\hline & Pharmacists & 10 & 2 & 12 & $(\mathrm{df}=3)$ \\
\hline & Laboratory & 20 & 11 & 31 & \\
\hline & Scientists & & & & \\
\hline & Total & 208 & 117 & 325 & \\
\hline
\end{tabular}

$x^{2}$ : Chi-squared test (level of significance: $\leq 0.05$; df: degree of freedom) 


\section{DISCUSSION}

The prevalence of substance use in many societies, including Nigeria is acclaimed to be on the increase. ${ }^{8,-9}$ Attracting younger populations worldwide, this scourge, laden with heavy tolls of disability, morbidity and early deaths secondary to substance use disorders, ${ }^{7,-11}$ is viewed as a public health emergency. ${ }^{12-13}$ Also of concern is the report of such tendencies and practices occurring within the healthcare work force, which should be at the helm of affairs tackling this menace. Studies, largely from the western hemisphere, indicate that this is a subset of society to keep in close surveillance due to growing rates of reported substance use among them. ${ }^{19-23}$ Reported use of substances among HCWs, though initially anecdotal but currently a recognised and documented phenomenon, has existed in the western world for over a century; ${ }^{21-23}$ thus, giving rise to the coinage "practitioner impairment". This refers to a compromise in the ability of a health worker to effectively, competently and safely practice according to acceptable professional standards due to substance use, abuse or dependency. ${ }^{23,24}$

In this study, the prevalence of substance use (including substance-containing food items) among HCWs, who admitted ever using one substance or the other in the past or currently (lifetime use) was $85.5 \%$. Point prevalence (or current use) was $54.7 \%$ of the total respondents. This differs significantly from the national and regional (north-western Nigeria) figures reported in the recent Drug Use Survey for Nigeria. ${ }^{14}$ This survey estimates the past year prevalence of any drug use in Nigeria at $14.4 \%$ (or 14.3 million people aged between $15-64$ years) and $12 \%$ for the north-western zone (approximately 3 million people aged between 15-64 years). ${ }^{13-14}$ The variance between these figures and those reported in this study maybe as a result of the differences in the durations under consideration. The one-year period in the national survey being relatively shorter, compared to that covered in this study, which is "ever used". An enquiry of a lifetime use of substances (at least once) is more likely to produce a higher yield of affirmative responses.
Also, a wider age range of respondents (15-64 years) was captured in the national survey; thus, embracing age groups known to have lower rates of substance use such as retirees and senior citizens, particularly in the fairly conservative northern parts of the country. ${ }^{14}$ HCWs younger than 35 years of age have been reported to have a greater risk of abusing diverse substances. ${ }^{25}$ This age group $(<35$ years) constituted about half $(50.8 \%)$ of this study's population. In addition, the wide age range in the national survey would increase the denominator for estimating the prevalence rate and thus, further lower the final figure (prevalence rate) obtained. Furthermore, the spectrum of substances (and substance-containing food items) captured in this study spans beyond that covered in the national survey, which excluded substances such as alcohol and tobacco. This could also translate to the higher prevalence reported in this study.

It should be noted that the foregoing is a comparison with the prevalence of substance use within the general population. This is so, owing largely to the already cited dearth of such information from low- and mediumincome countries, particularly among HCWs. While numerous research findings exist on this phenomenon among HCWs in high income countries, a paucity of such studies is the case with regards to developing countries, including Nigeria. ${ }^{26-28}$ Empirical evidence from other studies suggests that HCWs may experience equal or even higher risks as well as rates of substance use relative to the general public; particularly with regards to benzodiazepines and opiates. ${ }^{19-23,25-27}$

A Kenyan study reports higher lifetime and current substance use rates among HCWs relative to the general local (Kenyan) population; but lower, compared to rates among HCWs in many high income countries (HICs). ${ }^{26}$ Findings from studies in western countries report that about $7 \%$ to $32 \%$ of healthcare professionals abuse substances; ${ }^{27}$ 
while literature from the early 20th century report $10-40 \%$ prevalence rates of impaired physicians. ${ }^{3}$ Secondly, the habitual practice of substance use among HCWs very often goes unrecognised, being shrouded in secrecy coupled with non- or under-reporting; ${ }^{19-21,23-24,27}$ thus, further making a comparison with the general population inevitable. HCWs are at a relatively higher risk of substance abuse due to a number of occupational factors such as work-related stress, easy access to both over-the-counter and controlled prescription drugs, self-medication and a relatively in-depth knowledge of drugs and substances, as well as their mechanisms of action in and effects on the human body. ${ }^{19-29}$

Fortunately, substances (and substancecontaining food items) reported to be consumed among HCWs in this study were essentially licit. Coffee was most frequently used (53.7\%). Others included alcohol $(31.8 \%)$, kolanuts $(28.7 \%)$ and cigarettes (12.1\%). Caffeine-containing analgesics such as Panadol extra (14.7\%), a branded combination of paracetamol and caffeine and "Alabukun" (5.3\%), a popular, indigenous brand of acetylsalicylic acid (aspirin) and caffeine were also reported. Valium, a benzodiazepine (diazepam) was the least used substance $(0.8 \%)$ reported. Overall, caffeine-related substances and food items accounted for the majority. They include coffee, caffeine-containing analgesics and kolanuts; which are habitually chewed as stimulants and 'masticatories' by many in northern Nigeria for social, traditional, religious and medicinal purposes. ${ }^{30-31}$ Caffeine use and dependency are globally recognised phenomena. ${ }^{32-33}$ Heavy consumption of caffeine is reported to be associated with increased risks of cardiovascular problems and perinatal complications among vulnerable persons, besides the development of addictions. ${ }^{33}$

Alcohol ranked second in this study; likely owing to the conservative religious setting of the study area, which has a large population of Hausa and Fulani Muslims. ${ }^{14,34}$ The figure obtained for alcohol use in this study (31.8\%) is corroborated by that of a Nigerian national survey (39\%) and other studies in India (34\%) and Kenya (35.8\%). ${ }^{6,26,34}$ However, it differs from findings of about $59.1 \%$ alcohol use among HCWs in south-eastern Nigeria. This higher rate was attributed to alcohol being commonly available (in various brand forms), affordable and socio-culturally acceptable within that region of Nigeria. ${ }^{27}$ Studies from HICs report even higher rates of alcohol consumption as well as alcohol dependence. ${ }^{23-24}$ Cigarette consumption rate $(12.1 \%)$ in this study also compared with the national rate $(12.2 \%){ }^{34}$ The use of sedatives (benzodiazepines) was lower $(0.8 \%)$ than that reported among HCWs by authors in other parts of the world. ${ }^{20-21,23-24,28}$ This may be as a result of stringent control measures being enforced by the National Agency for Food and Drug Administration and Control (NAFDAC) in the prescription and dispensing of such drugs within the country. $^{12,35}$

Diverse factors have been attributed to the tendency for substance use by other researchers understudying various subgroups. They include curiosity, peer influence, work-related stress, age, sex, area of specialty (among HCWs), levels of education, social media influences, employment and migration status, urbanisation, poverty and lack of social support. ${ }^{12,19-20,22-23,26-29,36}$ In this study, though the age and cadre of HCWs were not found to be statistically significant factors in predicting substance use, it was observed that gender was a determinant for the use of substances $(p<0.05)$. This is similar to the findings of other studies. ${ }^{8,23,26,28,34,37}$ Males, particularly within the sociocultural context of this study area are more likely to freely engage in social pastime activities such as cigarette smoking and social drinking, among others. The 2018 Drug Use Survey in Nigeria reports a higher male: female ratio for substance use, with one out of every four substance users being female. It also cites that more men (annual prevalence of $21.8 \%$ or 10.8 million men) than women (annual prevalence of $7 \%$ or 3.4 million women) reported past-year drug use. $^{14}$ 


\section{Limitations:}

The category of healthcare workers in this study consisted of only physicians, nurses, pharmacists and laboratory scientists; therefore, the findings may not necessarily apply to or be generalized to other cadre of health care workers (such as community health officers and extension workers, environmental health officers etc). Furthermore, the probable medical use of some of the substances reported was not ruled out. These, among others, the authors recognise as limitations in the study.

\section{Conclusion}

This study reported a substance use rate among HCWs that is relatively higher than that obtainable within the general population; a trend comparable to other studies from diverse parts of the globe, where this subset of the population has been studied. Fortunately, substances commonly consumed were essentially licit. Gender was found to be a determining factor for substance use. These findings add to the rather sparse body of existing knowledge with regards to this phenomenon among HCWs in the developing world and would contribute to the knowledge base of the prevalence of this menace and the common substances implicated. Substance use among HCWs potentially carries grave implications for HCWs and patients alike. Priority focus and attention will need to be given to further research in unearthing the prevalence of this menace among HCWs as well as addressing the direct and remote factors fueling this challenge within this subset of the society, being in the fore of healthcare delivery. This is pertinent in view of the significant ongoing brain-drain in the health sector amidst poor health indices in the general population, typical of many LMICs.

Conflicts of Interest: the authors declare no conflict of interest

\section{REFERENCES}

1. Keane R, Reaper-Reynolds S, Williams J et al. Understanding substances and substance use: a handbook for teachers. Produced by the South Western Area Health Board; Funded by the Walk Tall Programme and the Irish Government under the National Development Plan 2000-2006. (Accessed $28^{\text {th }}$ of June, 2019)

2. The British Psychological Society and the Royal College of Psychiatrists (National Collaborating Centre for Mental Health, UK) 2008. Drug misuse: psychosocial interventions. (NICE Clinical Guidelines No. 51) 3, Introduction to drug $\mathrm{mis} u \mathrm{se}$. A va i l a ble fro m : https://www.ncbi.nlm.nih.gov/books/NBK532 $17 /$ (Accessed $28^{\text {th }}$ of June, 2019)

3. World Health Organisation (WHO). Health Topics: Substance abuse, https://www.who.int/topics/substance abuse/ en/ (Accessed $28^{\text {th }}$ of February, 2019)

4. The American Psychiatric Association. Diagnostic and statistical manual of mental disorders: DSM-IV-TR. (Fourth Edition), 2000; Division of Research, American Psychiatric Association, Washington DC. (Accessed from https://www.who.int/substance abuse/termin ology/abuse/en/ on the $28^{\text {th }}$ of February, 2019)

5. Wikipedia. Substance abuse, https://en.wikipedia.org/wiki/Substance_a buse (Accessed 14th of March, 2019)

6. Fox TP, Oliver G and Ellis SM. The destructive capacity of drug abuse: an overview exploring the harmful potential of drug abuse both to the individual and to society. ISRN Addiction 2013; vol. 2013, Article I D $450348,6 \quad$ p a g e s . https://doi.org/10.1155/2013/450348.

7. Nasirzadeh M, Eslami AA, Sharifirad Get al. The mental health and substance abuse among youths aged 18 to 29: a comparative study. J Educ Health Promot 2013; 2: 34

8. Dadwani RS and Thomas T. Prevalence of substance abuse: a communitybased study. Int J Community Med Public Health 2016;3(3):647-650

9. Oshikoya KA and Alli A. Perception of drug abuse amongst Nigerian undergraduates. World J of Med Sci 2006; (2): 133-139 
10. World Health Organisation (WHO). Alcohol and drug use disorders: Global Health Estimates (GHE) 2017 (Accessed 20 ${ }^{\text {th }}$ of March, 2019)

11. United Nations Office on Drugs and Crime (UNODC). World Drug Report 2017 (ISBN: 978-921-148291-1, eISBN: 978-92-1-060623-3, United Nations publication, Sales No. E.17.XI.6). (Accessed 20 ${ }^{\text {th }}$ of March, 2019)

12. Adeyeye MC. The problem of drugs/substance abuse in Nigeria: a symposium. Paper delivered by the Director-General, National Agency for Food and Drug Administration and Control (NAFDAC) on the $27^{\text {th }}$ of June, 2018 at The University of Benin, Benin City. Available from: https://www.nafdac.gov.ng/category/pressrelease/page/3 (Accessed 20th of March, 2019)

13. This Day Newspaper. Nigeria: the epidemic of drug abuse (Editorial of $13^{\text {th }}$ February, 2019 ). A v a i l a b l e f r o m : https://www.thisdaylive.com/index.php/2019 /02/13/the-epidemic-of-drug-abuse/ (Accessed $3^{\text {rd }}$ of June, 2019)

14. United Nations Office on Drugs and Crime (UNODC). Drug Use in Nigeria 2018, https://www.unodc.org/documents/data-andanalysis/statistics/Drugs/Drug_Use_Survey_Ni geria_2019_Exsum.pdf (accessed $3^{\text {rd }}$ of June, 2019)

15. Reardon CL and Creado S. Drug abuse in athletes. Subst Abuse Rehabil 2014; 5:95-105

16. Lathan SR. Celebrities and substance abuse. Proc (Bayl Univ Med Cent) 2009; 22(4):339-341

17. European Monitoring Centre for Drugs and Drug Addiction (EMCDDA). Selected issues: drugs and vulnerable groups of young people 2008 (ISBN: 978-92-9168-343-7; Catalog Number: TDSI08003ENC)

18. Panthee B, Suresh P, Gyawali S et al. Prevalence and correlates of substance use among health care students in Nepal: a cross sectional study. BMC Pub Health 2017; 17:950

19. Bennett J and O'Donovan D. Substance misuse by doctors, nurses, and other healthcare workers. Curr Opin Psychi 2001; 14:195-199

20. Snyder R. Drug abuse among health professionals. Continuing Education Activity 2016; Duquesne University, Pittsburgh, Pennsylvania, USA. (Accessed $7^{\text {th }}$ of August, 2019)
21.Butler Center for Research. Health Care Professionals Addiction and Treatment (research update): unique challenges for professionals in addiction diagnosis and $\mathrm{t} \quad \mathrm{e}$ a $\mathrm{t} \mathrm{m}$ e $\mathrm{n} \mathrm{t}$, https://www.hazeldenbettyford.org/educa tion/bcr/addiction-research/health-careprofessionals-substance-abuse-ru-615 (Accessed 7th of August, 2019)

22.Srivastava $A B$. Impaired physicians: obliterating the stigma. Am J Psychia (Residents' Journal) 2018;13(3):4-6

23. Baldisseri MR. Impaired healthcare professional. Crit Care Med 2007; 35(2 Suppl): S106-116

24.Dhai A, Szabo CP and McQuoid-Mason DJ. The impaired practitioner- scope of the problem and ethical challenges. S Afr Med J 2006; 96(10):1069-1072

25.Kenna GA and Lewis DC. Risk factors for alcohol and other drug use by healthcare professionals. Subst Abuse Treat Prev Policy 2008; $3: 3$

26. Mokaya AG, Mutiso V, Musau A et al. Substance use among a sample of healthcare workers in Kenya: a cross-sectional study. J Psychoactive Drugs 2016; 48(4):310-319

27. Ndukuba AC, Odinka PC, Ndukuba ET Donika al. Perception of Nigerian healthcare professionals about substance abuse and their willingness to seek substance related help: a pilot study. Orient J Med 2015; 27(3-4): 86-92

28. Aslam N. Helping the helpers: incidence of drug use among health care professionals. Anaesth Pain \& Intensive Care 2014; 18(4):470-71

29. Owie HO and Apanga PA. Occupational health hazards prevailing among healthcare workers in developing countries. J AIDS Clin Res 2016; 7:596 doi:10.4172/2155-6113.1000596

30. Erinfolami A, Eegunranti A, Ogunsemi $\mathrm{O}$ et al. Prevalence and associated risk factors of kola nut chewing among secondary school students in Osogbo, Nigeria. Ment Illn 2011; 22;3(1):21-24

31. Asogwa EU, Otuonye AH, Oluyole KA et al. Kolanut production, processing and 
marketing in the south-eastern states of Nigeria. Americ-Euras J Agric \& Env Sci 2012; 12(4): 463-468 32. Temple JL, Bernard C, Lipshultz SE et al. The safety of ingested caffeine: a comprehensive review. Front Psychia 2017; 8:80

33. Meredith SE, Juliano LM, Hughes JR et al. Caffeine use disorder: a comprehensive review and research agenda. J Caffeine Res 2013; 3(3): 114-130

34. Adamson TA, Ogunlesi AO, Morakinyo O et al. Descriptive national survey of substance use in Nigeria. J Addict Res Ther 2015; 6:234 doi: 10.4172/2155-6105.1000234

35.Federal Ministry of Health (FMOH). National Policy for Controlled Medicines and its Implementation Strategies, 2017. Funded by the
European Union (EU) under the framework of the "Response to Drugs and Related Organized Crimes in Nigeria" project; implemented by the United Nations Office on Drugs and Crime (UNODC). (Accessed $6^{\text {th }}$ of June, 2019)

36. Uchtenhagen A. Substance use problems in developing countries: editorial. Bull of WHO: Int'l J Pub Health 2004; 82(9):641. http:/ / www.who.int/iris/handle/10665/72 890 (Accessed 6th of June, 2019)

37. World Health Organisation (WHO). Atlas on substance use (2010): resources for the prevention and treatment of substance use disorders. WHO Press, 20 Avenue Appia, 1211 Geneva 27, Switzerland.

Cite this article as: Omole VN, Irohibe CK, Usman NO, Audu O, Jamda MA, Baduku AS Maigari JM. Substance Use Among Healthcare Workers In A Nigerian Tertiary Hospital. KJMS 2020; 14(2): 115 - 124. 